\title{
Comparison of $\pi$-Hole Tetrel Bonding with $\sigma$-Hole Halogen Bonds in Complexes of XCN (X = F, Cl, Br, I) and $\mathrm{NH}_{3}$
}

\author{
Vincent de Paul N. Nziko and Steve Scheiner* \\ Department of Chemistry and Biochemistry \\ Utah State University \\ Logan, UT 84322-0300
}

\begin{abstract}
In addition to the standard halogen bond formed when $\mathrm{NH}_{3}$ approaches $\mathrm{XCN}(\mathrm{X}=\mathrm{F}, \mathrm{Cl}, \mathrm{Br}, \mathrm{I})$ along its molecular axis, a perpendicular approach is also possible, toward a $\pi$-hole that is present above the $\mathrm{X}$-C bond. MP2/aug-cc-pVDZ calculations indicate the latter geometry is favored for $\mathrm{X}=\mathrm{F}$, and the $\sigma$-hole structure is preferred for the heavier halogens. The $\pi$-hole structure is stabilized by charge transfer from the $\mathrm{NH}_{3}$ lone pair into the $\pi^{*}(\mathrm{CN})$ antibonding orbital, and is characterized by a bond path from the $\mathrm{N}$ of $\mathrm{NH}_{3}$ to the $\mathrm{C}$ atom of $\mathrm{XCN}$, a form of tetrel bond. The most stable 2:1 $\mathrm{NH}_{3} / \mathrm{XCN}$ heterotrimer for $\mathrm{X}=\mathrm{F}$ and $\mathrm{Cl}$ is cyclic and contains a tetrel bond augmented by a pair of $\mathrm{NH} \cdot \mathrm{N}$ H-bonds. For $\mathrm{X}=\mathrm{Br}$ and $\mathrm{I}$, the favored trimer is noncyclic, stabilized by a tetrel and a halogen bond.
\end{abstract}

*steve.scheiner@usu.edu

Keywords: cooperativity; NBO; AIM; SAPT 


\section{INTRODUCTION}

Noncovalent interactions play important roles in a wide range of chemical and biochemical processes such as molecular recognition, conformational changes, and molecular stacking in crystals ${ }^{1-3}$. The hydrogen bond (HB) has emerged as the most widely studied type of noncovalent interaction. Its original formulation that involved only $\mathrm{O}, \mathrm{N}$ and $\mathrm{F}$ atoms has been expanded over the years to include $\mathrm{C}, \mathrm{Cl}, \mathrm{S}$, and $\mathrm{P}$ as proton donor atoms ${ }^{4-13}$. There are also other types of noncovalent interactions in which the bridging atom is not $\mathrm{H}$ but rather a member of group IV, V, VI or VII, commonly denoted as tetrel ${ }^{14-17}$, pnicogen ${ }^{18-}$ ${ }^{27}$, chalcogen ${ }^{28-36}$, and halogen bonds ${ }^{37-46}$, respectively.

These bond types share certain structural and electronic features. Along the extension of the Z-Y bond $(\mathrm{Z}=$ an electronegative atom and $\mathrm{Y}=$ a group IV, $\mathrm{V}, \mathrm{VI}$, or VII atom) their molecular electrostatic potential (MEP) usually contains a positive region, frequently referred to as a $\sigma$-hole. This idea has been expanded in the sense that the electron density of certain molecules is thinned out above the molecular plane, which accounts for a region of positive MEP in that area, sometimes denoted a $\pi$-hole. Whether in or out of the molecular plane, these areas of positive MEP are drawn toward sources of electron density in a neighboring molecule, typically either a lone pair or a $\pi$-bond.

Cyanogen halides (X-CN, $\mathrm{X}=\mathrm{F}, \mathrm{Cl}, \mathrm{Br}$ or I) play an important role in chemical reactions especially in electrophilic substitution reactions in which $\mathrm{CN}$ acts as an electrophile. This reaction is particularly important in biopolymer modification and in protein and peptide fragmentation ${ }^{47-49}$. In organic synthesis, these compounds serve ${ }^{50,51}$ as a source of an extra carbon atom in the synthesis of guanidines and hydroxyguanidines when reacted with primary and/or hydroxylamines ${ }^{52}$. The cyanogen halides are also used ${ }^{53}$ in the synthesis of nitriles, especially aryl nitriles.

Due to the importance of the $\mathrm{C} \equiv \mathrm{N}$ group, it has generated substantial examination of its electron donation to neighboring molecules via its $\mathrm{N}$ lone pair. Also well considered is its indirect effect on noncovalent interactions via its electron-withdrawing ability to strengthen $\sigma$-holes on neighboring atoms. However, there has been very little study of its interactions with other molecules which are oriented perpendicular to it. In current lexicon, can the $-\mathrm{C} \equiv \mathrm{N}$ group generate a region of positive electrostatic potential above itself, one that could be characterized as a $\pi$-hole? If that is the case, how strong might its interactions be with an incoming electron donor molecule? Also, given the strength of $\mathrm{C} \equiv \mathrm{N}$ as an electronwithdrawing agent, it would deepen the $\sigma$-hole of the $\mathrm{X}$ atom on a $\mathrm{XC} \equiv \mathrm{N}$ molecule on which it occurs. Would the ensuing $\sigma$-hole bond through this $\mathrm{X}$ atom be competitive with a potential $\pi$-hole interaction? And finally, how might the formation of either the $\sigma$ or $\pi$-hole complex affect the ability of the XCN molecule to engage in an interaction with a third molecule? 
While interactions involving $\sigma$-holes have drawn very extensive study, there is much less examination of $\pi$-hole analogues available in the literature ${ }^{54-66}$. There has been some recent study of $\pi$-holes connected with the $-\mathrm{NO}_{2}$ group ${ }^{67-75}$, for example, or noble gas systems such as $\mathrm{XeF}_{4}$ and $\mathrm{Xe}(\mathrm{OMe})_{4}{ }^{76}$. But the $\mathrm{C} \equiv \mathrm{N}$ group remains virtually unexplored in terms of its potential for $\pi$-hole interactions.

This work considers the halogen cyanides $\mathrm{XCN}$ where $\mathrm{X}$ spans the $\mathrm{F}, \mathrm{Cl}, \mathrm{Br}$, I range of halogen atoms. In terms of $\sigma$-hole interactions, $\mathrm{F}$ is known as a very reluctant halogen-bonding atom, while I forms very strong halogen bonds, with $\mathrm{Cl}$ and $\mathrm{Br}$ intermediate. On the other hand, there is little known about how these halogens might affect the MEP above the $\mathrm{C} \equiv \mathrm{N}$ axis, and the ability of this region to engage in $\pi$-hole interactions. The set of XCN molecules thus offers a useful means of comparison of $\sigma$ and $\pi$-hole bonding. $\mathrm{NH}_{3}$ is chosen as the common electron donor, not only here but in numerous other studies $44,65,70,75,77-80$ of these sorts of interactions. By adding a second $\mathrm{NH}_{3}$ molecule to the $\mathrm{XCN} / \mathrm{NH}_{3}$ heterodimer, it becomes possible to examine the cooperativity of both sorts of noncovalent bonds. To the best of our knowledge this set of systems represents the first study of $\pi$-hole interaction with direct involvement of sp-hybridized carbon.

\section{METHODS}

Gaussian 09, Rev D.01 and B.01 ${ }^{81}$ was used to carry out the ab initio calculations. Geometries of all species were fully optimized at the MP2 level with the aug-cc-pVDZ basis set for all atoms except for I for which the aug-cc-pVDZ-PP set was adopted to account for relativistic effects. Minima were confirmed by the lack of any imaginary frequencies. Interaction energies were computed as the difference in energy between the optimized complex and the sum of monomer energies, within the complex geometry reference frame. Three-body components for the trimer systems $\left(\Delta^{3} E\right)$ were evaluated via Eqs (1) and (2).

$$
\begin{aligned}
& \Delta^{3} \mathrm{E}(\mathrm{ABC})=\mathrm{E}_{\mathrm{int}}(\mathrm{ABC})-\left(\Delta^{2} \mathrm{E}(\mathrm{AB})+\Delta^{2} \mathrm{E}(\mathrm{AC})+\Delta^{2} \mathrm{E}(\mathrm{BC})\right) \\
& \Delta^{2} \mathrm{E}(\mathrm{AB})=\mathrm{E}_{\mathrm{AB}}-\left(\mathrm{E}_{\mathrm{A}}+\mathrm{E}_{\mathrm{B}}\right)
\end{aligned}
$$

Higher level calculations expanded the basis set to aug-cc-pVTZ and aug-cc-pVQZ, using the MP2/aug-cc-pVDZ geometries. CCSD(T) was also employed with the aug-cc-pVDZ basis set. One can extrapolate the data from the ordered DZ, TZ, QZ basis sets to an estimate of complete basis set (CBS) results. Extrapolation was based on the idea ${ }^{82}$ that correlation energy is roughly proportional to $\mathrm{X}^{-3}$ for basis sets of the aug-cc-pVXZ type. Utilizing a two-step method with triple and quadruple sets ${ }^{83}$ :

$$
\Delta \mathrm{E}_{\mathrm{MP} 2 / \mathrm{CBS}}=\left(64 \Delta \mathrm{E}_{\mathrm{MP2} / \mathrm{aug}-\mathrm{cc}-\mathrm{pVQZ}}-27 \Delta \mathrm{E}_{\mathrm{MP} 2 / \text { aug-cc-pVTZ }}\right) / 37
$$


A correction was added to account for discrepancies between MP2 and CCSD(T)

$\mathrm{E}_{\mathrm{CCSD}(\mathrm{T}) / \mathrm{CBS}}=\mathrm{E}_{\mathrm{MP} 2 / \mathrm{CBS}}+\left(\mathrm{E}_{\mathrm{CCSD}(\mathrm{T}) / \text { aug-cc-pVDZ })}-\mathrm{E}_{\mathrm{MP} 2 / \text { aug-cc-pVDZ }}\right)$

All interaction energies were corrected for basis set superposition error using the standard counterpoise method ${ }^{84}$. Natural Bond Order (NBO) treatment of charge transfer ${ }^{85-87}$ was carried out via the M06-2X DFT method with the aug-cc-pVDZ basis set, as this procedure includes electron correlation and was designed so as to treat intermolecular interactions with some accuracy. Atoms in Molecules (AIM) analysis ${ }^{88,89}$ of the wave function was performed via the AIMall package ${ }^{90}$ to assess the presence of bond paths. The total interaction energy was dissected into various components by symmetry-adapted perturbation theory (SAPT) ${ }^{91-93}$ using the MOLPRO program ${ }^{93}$, at the PBE0 DFT level ${ }^{94-96}$ with the augcc-pVDZ set. Maxima and minima of the molecular electrostatic potential were derived via the WFA-SAS program ${ }^{97}$, using the MP2/aug-cc-pVDZ electron density.

\section{$\underline{\text { Monomers }}$}

The MEP of each XCN monomer is illustrated in Fig 1, where red and blue regions indicate negative and positive potentials, respectively. These MEPs share certain features. All exhibit a red negative region along the projection of the $\mathrm{C}-\mathrm{N}$ bond, corresponding to a $\mathrm{N}$ lone pair. There is a positive region on the opposite end of each molecule, a $\sigma$-hole along the $\mathrm{C}$-X bond. There is another positive area located above the $\mathrm{X}-\mathrm{C}$ bond, which might be referred to as a $\pi$-hole. The magnitudes of these potentials can be assessed via the maxima and minima on the $\rho=0.001$ au isodensity surfaces, which are indicated by the black and blue dots, respectively. As one progresses to larger halogen atoms, $\mathrm{F} \rightarrow \mathrm{Cl} \rightarrow \mathrm{Br} \rightarrow \mathrm{I}$, the value of the minimum near $\mathrm{N}$ becomes slightly more negative, varying from -27.2 to $-31.6 \mathrm{kcal} / \mathrm{mol}$, which can be explained by the progressively smaller electron-withdrawing power of the halogen. More sensitive to the identity of $\mathrm{X}$ is the magnitude of the $\pi$-hole which reaches as high as $28.2 \mathrm{kcal} / \mathrm{mol}$ for $\mathrm{X}=\mathrm{F}$ and drops down to only $10.7 \mathrm{kcal} / \mathrm{mol}$ for $\mathrm{X}=\mathrm{I}$. Also sensitive to the halogen, but varying in the opposite direction is the magnitude of the $\sigma$-hole, which is only $+14.5 \mathrm{kcal} / \mathrm{mol}$ for $\mathrm{X}=\mathrm{F}$ but increases all the way up to +47.9 $\mathrm{kcal} / \mathrm{mol}$ for $\mathrm{X}=\mathrm{I}$.

\section{Heterodimers}

One would expect that nucleophilic $\mathrm{NH}_{3}$, and specifically its lone pair, to approach one of the two positive regions of XCN. And in fact, this expectation is confirmed. The two sorts of minima obtained are illustrated in Fig 2. In the upper set of structures, the $\mathrm{N}$ lone pair approaches the $\pi$-hole lying above the C$\mathrm{X}$ bond, while the second set of geometries fall in the category of standard $\sigma$-hole halogen bonds. The 
interatomic distances in Fig 2 conform to the pattern of MEP maxima: These distances get longer for the $\mathrm{F}$ $\rightarrow \mathrm{Cl} \rightarrow \mathrm{Br} \rightarrow \mathrm{I}$ progression of the $\pi$-hole configurations, and shorter for the $\sigma$-holes.

These distances are displayed in Tables 1 and 2, along with the counterpoise-corrected interactions energies in the first column. The halogen bonds get very much stronger as the halogen atom becomes larger, but the $\pi$-hole interaction energies in Table 1 are less sensitive to halogen atom, again fitting the MEP patterns in Fig 1. Very similar patterns may be noted in the electronic markers of the noncovalent bond. The blue numbers in Fig 2 correspond to the energetic manifestation of the charge transfer from the $\mathrm{N}$ lone pair to the $\pi^{*}(\mathrm{CN})$ antibonding orbital for the $\pi$-hole complexes, and to $\sigma^{*}(\mathrm{CX})$ for the $\sigma$-bonded congeners. This quantity increases dramatically in the order $\mathrm{F}<\mathrm{Cl}<\mathrm{Br}<\mathrm{I}$ for the $\sigma$-hole structures, but diminishes slowly for the $\pi$-hole geometries. The same applies to the electron densities at the appropriate AIM bond critical points, displayed after the / mark in Fig 2. The corresponding bond paths in the $\pi$-hole dimers connect $\mathrm{N}$ of $\mathrm{NH}_{3}$ with the $\mathrm{C}$ atom. For this reason, these structures might be considered a sort of tetrel bond, although the presence of such a bond path does not necessarily prove ${ }^{98}$ the existence of a noncovalent bond.

Along with the charge transfer in the $\sigma$-hole complexes into the $\sigma^{*}(\mathrm{CX})$ antibonding orbital one can see the lengthening of this bond reported in the last column of Table 2, again increasing as the halogen becomes larger. In contrast, the $\mathrm{C} \equiv \mathrm{N}$ bond of $\mathrm{XCN}$ shows only marginal changes in length upon formation of the $\pi$-hole complexes in Table 1. It is worth noting that neither NBO nor AIM data are consistent with any sort of $\mathrm{NH} \cdot \mathrm{N}$ H-bond in the $\pi$-hole complexes, despite a $\mathrm{H} \cdot \mathrm{N}$ distance of less than $3 \AA$ (see Fig 2).

Comparison of the energetics of the two sorts of complexes shows that the halogen-bonded $\mathrm{NCX} \cdot \mathrm{NH}_{3}$ structures are favored for $\mathrm{X}=\mathrm{Cl}, \mathrm{Br}$, and $\mathrm{I}$, but that there is a strong preference for the tetrel bond for FCN. This distinction again conforms to the increasing/decreasing magnitude of the $\pi / \sigma$ hole maximum in the XCN sequence. Similar observations apply to both the NBO and AIM measures of the noncovalent bond strength: these quantities are larger for the $\sigma$-hole complexes for $\mathrm{X}=\mathrm{Cl}, \mathrm{Br}$, and $\mathrm{I}$, but the reverse is true for $\mathrm{X}=\mathrm{F}$.

The nature of the bonding in complexes such as these can also be examined through the lens of electron density shifts. These shifts, displayed in Fig 3 for the four $\pi$-hole complexes, were evaluated as the difference between the total electron density of the complex, minus the sum of the densities of the two monomers, located in the same positions as in the dimer. The yellow regions correspond to an increase of density accruing from complexation, while depletions are signaled by green. The dominant feature of these diagrams is the yellow buildup of density in the region of the $\mathrm{N}$ lone pair, coupled with the green loss above the $\mathrm{C}$-X bond, consistent with the idea of the interaction with the $\mathrm{XCN} \pi$-hole. Note that the extent 
of these two regions diminishes as one goes from left to right, from $\mathrm{F}$ to I. This pattern is consistent with the AIM data concerning the strength of the $\mathrm{N} \cdot \mathrm{C}$ tetrel bond.

Another interesting feature of Fig 3 is the reduced involvement of the central $\mathrm{C}$ atom with heavier halogens. That is, as one moves from left to right in Fig 3, the green depletion region over the XCN molecule shifts away from the $\mathrm{C}$ and toward the halogen. This green region above the $\mathrm{C}$ is rather extensive for FCN, but shrinks to a far smaller area for ICN.

The density shifts in Fig 3 also show indications of a $\mathrm{HB}$ between two of the $\mathrm{NH}_{3}$ protons and the $\mathrm{XCN}$ $\mathrm{N}$ atom, albeit a weak one. This interaction is marked by the small green loss of density around these bridging $\mathrm{H}$ atoms and a yellow gain above the $\mathrm{N}$ atom. On the other hand, AIM does not suggest the presence of a $\mathrm{H}$-bond path, even a weak one, nor was there any significant NBO charge transfer from $\mathrm{N}$ to $\sigma^{*}(\mathrm{NH})$. One may conclude that any such $\mathrm{HB}$ would indeed be a weak one, with negligible contribution to the total binding.

Decomposition of the total interaction energies can add insights into the nature of the bonding. The SAPT procedure partitions the total attractive forces into electrostatic (ES), induction (IND), and dispersion (DISP), leaving exchange (EX) as the repulsive term which prevents coalescence into a single entity. Perusal of the data in Table 3 shows that ES and IND make the largest contributions to the $\pi$-hole complexes, roughly equal to one another, with DISP are not far behind. These quantities are largest for $\mathrm{X}=\mathrm{F}$, and roughly equivalent for the three other halogens. In the $\sigma$-hole complexes of Table 4 , on the other hand, all of the terms grow rapidly as the halogen atom becomes heavier. The ES term for $\mathrm{X}=\mathrm{I}$ is some 12 times larger than for $\mathrm{X}=\mathrm{F}$, and this ratio is 40 for induction energy. ES is the largest contributor for $\mathrm{F}$, but it is far exceeded by IND for Br and I; DISP is the smallest of the three attractive terms. In conclusion, the $\pi$-hole complexes are characterized by a nearly equivalent ES, IND, and DISP, and a low sensitivity to the identity of $\mathrm{X}$. The nature of the halogen atom makes a huge difference in the $\sigma$-hole complexes, with all three attractive terms becoming more so for the heavier atoms; it is IND that makes the dominant contribution for $\mathrm{Br}$ and I. In most cases, the total SAPT interaction in the final column of Table 3 and 4 matches quite closely the supermolecular quantities in Tables 1 and 2 . The sole exception is the $\mathrm{NCI} \cdots \mathrm{NH}_{3}$ $\sigma$-hole complex where the former exceeds the latter by several kcal $/ \mathrm{mol}$. This difference may be associated with the very large induction energy for this complex in the final row of Table 4.

Of course, MP2/aug-cc-pVDZ does not represent the final word in terms of the interaction energies. It is worthwhile to examine how the interaction energetics might be affected if higher levels of theory were applied. The first few columns of Tables 5 and 6 show that enlargement of the basis set first to triple and then to quadruple- $\zeta$ leads to small enhancements of the interaction energies at the MP2 level. Extrapolation 
to the complete basis set then yields another small increment. Including electron correlation via CCSD(T), on the other hand, produces smaller interaction energies than does MP2, although this decrement is fairly small. The $\operatorname{CCSD}(\mathrm{T})$ data with a complete basis set, reported in the last columns of Tables 5 and 6, are close to but a bit larger than the MP2/aug-cc-pVDZ results, generally closer to MP2/aug-cc-pVTZ.

\section{$\underline{\text { Heterotrimers }}$}

It is of interest to gauge the effect that a second $\mathrm{NH}_{3}$ molecule might exert upon the $\pi$-hole heterodimers. The optimized geometries adopted by the $\left(\mathrm{NH}_{3}\right)_{2} \mathrm{XCN}$ heterotrimers that contain such a $\pi$ bond are displayed in Figs 4-7. T1 pairs the tetrel and halogen-bonded structures of the dimer together in a single trimer. The latter XB is replaced by a second $\pi$-hole bond in $\mathrm{T} 2$. Instead of $\mathrm{XCN}$ as central molecule, it is $\mathrm{NH}_{3}$ that serves this function in T3. T4 and T5 are cyclic in that each molecule interacts directly with both of the remaining molecules. T4 combines a tetrel bond with a pair of $\mathrm{NH} \cdot \mathrm{N}$ HBs. The geometry of $\mathrm{T} 5$ is similar except that the third $\mathrm{NH}_{3}$ molecule is inverted, i.e. it engages in a $\mathrm{HB}$ with the other $\mathrm{NH}_{3}$ unit via the smaller lobe of its $\mathrm{N}$ lone pair.

The interaction energies of the five trimer structures are reported in Table 7 for all of the $\mathrm{XCN}\left(\mathrm{NH}_{3}\right)_{2}$ heterotrimers. For both FCN and ClCN, cyclic structure T4 is most stable; however the preferred trimer is $\mathrm{T} 1$ for $\mathrm{BrCN}$ and ICN. This preference is likely a result of the very strong halogen bonds in which the latter two molecules engage, an interaction which is only present in T1. It may be noted that T1 does not represent a minimum on the surface of the FCN trimer, a consequence of the very weak XB formed by FCN. The inverse HB present in T5 is weak enough that this configuration is the least stable in all cases, and is not even present for ICN.

In both $\mathrm{T} 1$ and $\mathrm{T} 2$, the central XCN molecule serves as double electron acceptor. One would hence expect some degree of negative cooperativity. This anticipation is confirmed by comparison of the interaction energies with those in parentheses in Table 7. The latter quantities represent a simple sum of the pertinent interaction energies in the dimers: $\sigma$-hole $+\pi$-hole for T1 and $2 \times \pi$-hole for T2. The actual interaction energies are somewhat smaller than the sums, consistent with negative cooperativity. This negative cooperativity is verified by comparison of the NBO/AIM data for the trimers and the dimers. Taking $\mathrm{X}=\mathrm{Cl}$ as an example, the NBO charge transfer is $0.99 \mathrm{kcal} / \mathrm{mol}$ in the dimer of Fig 2, but is reduced below $0.6 \mathrm{kcal} / \mathrm{mol}$ in $\mathrm{T} 1$ and $\mathrm{T} 2$. The $\mathrm{BCP}$ density is similarly diminished and in fact the bond path disappears entirely for T2. The $\sigma$-hole charge transfer energy is $3.25 \mathrm{kcal} / \mathrm{mol}$ for the $\mathrm{NCCl} \cdots \mathrm{NH}_{3}$ dimer, and it diminishes but only slightly in T1; likewise for $\rho_{\text {ВсР. }}$ Very similar trends are observed for the other $\mathrm{XCN}$ dimers and trimers. 
Rather than comparing the structures of the heterotrimers to fully optimized dimers, another view of the cooperativity may be achieved by a multi-body analysis in which pairwise interaction energies are evaluated within the geometry of the optimized trimer. The difference between the sum of all three pairwise interaction energies (whether the geometry is cyclic or linear) and the total interaction energy of the trimer is equal to a three-body term, $\Delta^{3} \mathrm{E}$, which can be equated with an energetic measure of cooperativity. These three-body terms are listed in Table 8 where negative quantities refer to an enhancement of the interaction and hence to a positive cooperativity. $\Delta^{3} \mathrm{E}$ is slightly positive for $\mathrm{T} 2$, consistent with the negative cooperativity. On the other hand $\Delta^{3} \mathrm{E}$ is slightly negative for $\mathrm{T} 1$ although negative cooperativity might be anticipated there. This apparent contradiction may be related to the incorporation into the formalism of a small but repulsive two-body interaction between the two $\mathrm{NH}_{3}$ molecules which are far apart. A similar inter- $\mathrm{NH}_{3}$ repulsion may be similarly responsible for the small values of $\Delta^{3} \mathrm{E}$ for $\mathrm{T} 2$ which might otherwise be more positive. T3-T5 all display positive cooperativity, most notably $\mathrm{T} 4$ which is the most stable trimer in a number of cases.

\section{CONCLUSIONS AND DISCUSSION}

$\mathrm{NH}_{3}$ can approach the XCN molecules from one of two directions. A standard $\sigma$-hole halogen bond is formed if the $\mathrm{NH}_{3}$ approaches the $\mathrm{X}$ atom along the NCX axis. The strength of this bond grows rapidly in the usual $\mathrm{F}<\mathrm{Cl}<\mathrm{Br}<$ I sequence, ranging from $1.1 \mathrm{kcal} / \mathrm{mol}$ for $\mathrm{X}=\mathrm{F}$ to $8.2 \mathrm{kcal} / \mathrm{mol}$ for $\mathrm{I}$. There is also a region of positive MEP above the axis of the XCN molecule. The maximum of this $\pi$-hole area if larger than that of the $\sigma$-hole for FCN, but the opposite is true for the other XCN molecules. Unlike the sensitivity of the MEP $\pi$ maximum to the identity of $X$, the interaction energies of the $\pi$-hole dimers are fairly uniform in the range between 2.4 and $3.1 \mathrm{kcal} / \mathrm{mol}$. The $\pi$-hole complex is more stable than the $\sigma$ hole analogue for $\mathrm{FCN}$, but it is the $\sigma$-hole structure that is preferred for the other $\mathrm{XCN}$ molecules.

NBO analysis traces the stability of the $\pi$-hole geometries in large measure to charge transfer from the $\mathrm{NH}_{3}$ lone pair to the $\pi^{*}(\mathrm{CN})$ antibonding orbital, whose behavior parallels the energetics of binding. The AIM topology of the electron density ascribes the interaction to a bond between the $\mathrm{N}$ of $\mathrm{NH}_{3}$ and $\mathrm{C}$ of $\mathrm{XCN}$, and also scales nicely with $\mathrm{E}_{\mathrm{int}}$. The electrostatic component of the total interaction energy is the largest, but induction and dispersion are not far behind. Like the total interaction, the components are also relatively insensitive to the identity of $X$. This behavior differs markedly from the halogen-bonded dimers where both ES and IND grow quickly with the size of the halogen atom, and IND exceeds ES for Br and I; DISP is considerably smaller.

A second $\mathrm{NH}_{3}$ molecule has several options for binding to the $\mathrm{NH}_{3} / \mathrm{XCN}$ heterotrimer. The resulting trimer may contain both a $\sigma$ and $\pi$-hole arrangement, or two of the latter, with the two $\mathrm{NH}_{3}$ molecules on 
opposite sides of XCN. There are also three different geometries wherein the two $\mathrm{NH}_{3}$ units engage in HBs with one another. For $\mathrm{X}=\mathrm{F}$ and $\mathrm{Cl}$, the preferred structure is one of the latter, which includes i) a $\pi$-hole interaction, ii) a $\mathrm{NH}^{\cdot} \cdot \mathrm{N}$ HB between the two $\mathrm{NH}_{3}$ molecules, and iii) a $\mathrm{NH} \cdot \mathrm{N}$ HB to the XCN $\mathrm{N}$ atom. The strength of the halogen bonds for $\mathrm{X}=\mathrm{Br}$ and $\mathrm{I}$ is an overwhelming factor so that the most stable heterotrimer contains this bond as well as a tetrel bond. The energetics, as well as the NBO and AIM characteristics, obey the expected cooperativity trends in that they are enhanced or diminished respectively when a given molecule serves as electron donor and acceptor, or as double acceptor.

As mentioned earlier, the $\pi$-hole characteristics of the $\mathrm{C} \equiv \mathrm{N}$ group have not been explored previously at any length, so comparison with other data in the literature is difficult. On the other hand, there have been a number of studies of the $-\mathrm{NO}_{2}$ group which together offer a point of comparison. The $\pi$-hole of the $\mathrm{NO}_{2}$ group is centered directly over the $\mathrm{N}$ atom ${ }^{69,72,73,75}$ so dimers of relevant molecules tend to place an electronegative atom of one molecule over the $\mathrm{N}$ of the other. There are indications that these interactions tend to be dominated by dispersion. Like $\mathrm{XCN}$, the $\pi$-hole over the $\mathrm{NO}_{2}$ subunit in $\mathrm{XNO}_{2}$ becomes weaker in the order $\mathrm{Cl}>\mathrm{Br}>\mathrm{I}^{70,73}$, but this trend is stronger than in the case of XCN. When placed on a phenyl ring, the $\mathrm{NO}_{2}$ group engages in $\pi$-hole complexes with a variety of nucleophiles with binding energies that range up to more than $6 \mathrm{kcal} / \mathrm{mol}^{71}$, wherein AIM places the bond to the $\mathrm{N}$ atom in most cases, but also to the phenyl $\mathrm{C}$ to which the $\mathrm{NO}_{2}$ group is connected. In addition to a lone pair, the $\pi$-bonding pair of a simple alkene or alkyne ${ }^{67}$ can also interact with the $\pi$-hole of $\mathrm{NO}_{2}$, in which case the dispersion energy exceeds the ES component.

With specific respect to the $\mathrm{NH}_{3}$ nucleophile, interaction energies of $\mathrm{XNO}_{2}$ with $\mathrm{NH}_{3}$ are slightly larger than is the case for $\mathrm{XCN}^{73}$. Overall, the $\mathrm{XNO}_{2}$ series has similar behavior as $\mathrm{XCN}^{75}$. The halogenbonded structure is favored for $\mathrm{X}=\mathrm{Br}$ and $\mathrm{I}$, but the $\pi$-hole preferred for $\mathrm{X}=\mathrm{Cl}$. Unlike the situation for $\mathrm{XCN}$, trimers of the $\mathrm{T} 1$ type display both positive and negative cooperativity, depending upon the nature of X. Curiously, $\mathrm{BrNO}_{2}$ favors the $\sigma$-hole halogen bond with $\mathrm{NH}_{3}$ but the $\pi$-hole is preferred ${ }^{74}$ for certain other nucleophiles.

\section{ACKNOWLEDGMENTS}

Computer, storage and other resources from the Division of Research Computing in the Office of Research and Graduate Studies at Utah State University are gratefully acknowledged. 


\section{REFERENCES}

1. P. Auffinger, F. A. Hays, E. Westhof and P. S. Ho, Proc. Nat. Acad. Sci., USA, 2004, 101, 1678916794.

2. A. D. Buckingham, P. W. Fowler and J. M. Hutson, Chem. Rev., 1988, 88, 963-988.

3. M. G. Chudzinski, C. A. McClary and M. S. Taylor, J. Am. Chem. Soc., 2011, 133, 10559-10567.

4. M. Nishio, Y. Umezawa, K. Honda, S. Tsuboyama and H. Suezawa, CrystEngComm, 2009, 11, 1757-1788.

5. B. J. van der Veken, S. N. Delanoye, B. Michielsen and W. A. Herrebout, J. Mol. Struct., 2010, 976, 97-104.

6. $\quad$ S. Scheiner, Y. Gu and T. Kar, J. Mol. Struct. (Theochem), 2000, 500, 441-452.

7. $\quad$ Y. Gu, T. Kar and S. Scheiner, J. Mol. Struct., 2000, 552, 17-31.

8. $\quad$ M. Domagala and S. J. Grabowski, Chem. Phys., 2010, 367, 1-6.

9. E. Arunan, G. R. Desiraju, R. A. Klein, J. Sadlej, S. Scheiner, I. Alkorta, D. C. Clary, R. H. Crabtree, J. J. Dannenberg, P. Hobza, H. G. Kjaergaard, A. C. Legon, B. Mennucci and D. J. Nesbitt, Pure Appl. Chem., 2011, 83, 1637-1641.

10. Z. Latajka and S. Scheiner, J. Chem. Phys., 1987, 87, 5928-5936.

11. H. S. Biswal, E. Gloaguen, Y. Loquais, B. Tardivel and M. Mons, J. Phys. Chem. Lett., 2012, 3, 755-759.

12. S. Scheiner, S. J. Grabowski and T. Kar, J. Phys. Chem. A, 2001, 105, 10607-10612.

13. E. Kryachko and S. Scheiner, J. Phys. Chem. A, 2004, 108, 2527-2535.

14. D. Mani and E. Arunan, Phys. Chem. Chem. Phys., 2013, 15, 14377-14383.

15. D. Mani and E. Arunan, J. Phys. Chem. A, 2014, 118, 10081-10089.

16. S. J. Grabowski, Phys. Chem. Chem. Phys., 2014, 16, 1824-1834.

17. A. Bauzá, T. J. Mooibroek and A. Frontera, Angew. Chem. Int. Ed., 2013, 52, 12317-12321.

18. M. D. Esrafili and F. Mohammadian-Sabet, Chem. Phys. Lett., 2015, 638, 122-127.

19. H. Zhuo and Q. Li, Phys. Chem. Chem. Phys., 2015, 17, 9153-9160.

20. I. Alkorta, J. Elguero and S. J. Grabowski, Phys. Chem. Chem. Phys., 2015, 17, 3261-3272.

21. J. E. Del Bene, I. Alkorta and J. Elguero, J. Phys. Chem. A, 2014, 119, 224-233.

22. S. Sarkar, M. S. Pavan and T. N. Guru Row, Phys. Chem. Chem. Phys., 2015, 17, 2330-2334.

23. M. Solimannejad, E. Bayati and M. D. Esrafili, Mol. Phys., 2014, 112, 2058-2062.

24. G. Sanchez-Sanz, C. Trujillo, I. Alkorta and J. Elguero, Phys. Chem. Chem. Phys., 2014, 16, 1590015909.

25. S. J. Grabowski, Chem. Eur. J., 2013, 19, 14600-14611.

26. S. Zahn, R. Frank, E. Hey-Hawkins and B. Kirchner, Chem. Eur. J., 2011, 17, 6034-6038.

27. S. Scheiner, Int. J. Quantum Chem., 2013, 113, 1609-1620.

28. A. Lange, M. Günther, F. M. Büttner, M. O. Zimmermann, J. Heidrich, S. Hennig, S. Zahn, C.

Schall, A. Sievers-Engler, F. Ansideri, P. Koch, M. Laemmerhofer, T. Stehle, S. A. Laufer and F. M. Boeckler, J. Am. Chem. Soc., 2015, 137, 14640-14652.

29. J. W. Keller, J. Phys. Chem. A, 2015, 119, 10390-10398.

30. V. d. P. N. Nziko and S. Scheiner, J. Phys. Chem. A, 2014, 118, 10849-10856.

31. S. P. Thomas, K. Satheeshkumar, G. Mugesh and T. N. Guru Row, Chem. Eur. J., 2015, 21, 67936800.

32. V. d. P. N. Nziko and S. Scheiner, J. Org. Chem., 2015, 80, 2356-2363.

33. A. Bauzá, I. Alkorta, A. Frontera and J. Elguero, J. Chem. Theory Comput., 2013, 9, 5201-5210.

34. M. Iwaoka and N. Isozumi, Molecules, 2012, 17, 7266-7283.

35. G. Sánchez-Sanz, C. Trujillo, I. Alkorta and J. Elguero, ChemPhysChem., 2012, 13, 496-503.

36. U. Adhikari and S. Scheiner, J. Phys. Chem. A, 2012, 116, 3487-3497. 
37. W. Zierkiewicz, D. C. Bieńko, D. Michalska and T. Zeegers-Huyskens, J. Comput. Chem., 2015, 36, 821-832.

38. M. Tawfik and K. J. Donald, J. Phys. Chem. A, 2014, 118, 10090-10100.

39. A. Mukherjee, S. Tothadi and G. R. Desiraju, Acc. Chem. Res., 2014, 47, 2514-2524.

40. S. J. Grabowski, Chem. Phys. Lett., 2014, 605-606, 131-136.

41. A. J. Stone, J. Am. Chem. Soc., 2013, 135, 7005-7009.

42. A. Bauzá, D. Quiñonero, P. M. Deyà and A. Frontera, CrystEngComm, 2013, 15, 3137-3144.

43. P. Politzer and J. S. Murray, ChemPhysChem., 2013, 14, 278-294.

44. J. A. Joseph and S. A. C. McDowell, J. Phys. Chem. A, 2015, 119, 2568-2577.

45. D. Hauchecorne and W. A. Herrebout, J. Phys. Chem. A, 2013, 117, 11548-11557.

46. G. Desiraju, R., P. S. Ho, L. Kloo, C. Legon Anthony, R. Marquardt, P. Metrangolo, P. Politzer, G. Resnati and K. Rissanen, in Pure Appl. Chem.2013, vol. 85, pp. 1711-1713.

47. W. A. Schroeder, J. B. Shelton and J. R. Shelton, Arch. Biochem. Biophys., 1969, 130, 551-555.

48. R. Kaiser and L. Metzka, Anal. Biochem., 1999, 266, 1-8.

49. G. Lunn and E. B. Sansone, Anal. Biochem., 1985, 147, 245-250.

50. D. N. Deaton, A. M. Hassell, R. B. McFadyen, A. B. Miller, L. R. Miller, L. M. Shewchuk, F. X. Tavares, D. H. Willard and L. L. Wright, Bioorg. Med. Chem. Lett., 2005, 15, 1815-1819.

51. B. B. Snider and S. M. O'Hare, Tetrahedron Lett., 2001, 42, 2455-2458.

52. J. March, Advanced Organic Chemistry: Reactions, Mechanisms, and Structure, Wiley, New York, 1985.

53. T. K. Brotherton and J. W. Lynn, Chem. Rev., 1959, 59, 841-883.

54. A. Bauzá, T. J. Mooibroek and A. Frontera, ChemPhysChem., 2015, 16, 2496-2517.

55. A. Bauzá and A. Frontera, ChemPhysChem., 2015, 16, 3625-3630.

56. A. Bauzá and A. Frontera, ChemPhysChem., 2015, 16, 3108-3113.

57. H. Wang, C. Li, W. Wang and W. J. Jin, Phys. Chem. Chem. Phys., 2015, 17, 20636-20646.

58. Y. Geboes, F. D. Proft and W. A. Herrebout, J. Phys. Chem. A, 2015, 119, 5597-5606.

59. S. J. Grabowski, ChemPhysChem., 2015, 16, 1470-1479.

60. F. Zhou, R. Liu, P. Li and H. Zhang, New J. Chem., 2015, 39, 1611-1618.

61. I. Alkorta, J. Elguero and J. E. Del Bene, J. Phys. Chem. A, 2013, 117, 10497-10503.

62. L. M. Azofra, I. Alkorta and S. Scheiner, Phys. Chem. Chem. Phys., 2014, 16, 18974-18981.

63. L. M. Azofra, I. Alkorta and S. Scheiner, Theor. Chem. Acc., 2014, 133, 1-8.

64. N. Ma, Y. Zhang, B. Ji, A. Tian and W. Wang, ChemPhysChem., 2012, 1411-1414.

65. J. S. Murray, P. Lane, T. Clark, K. E. Riley and P. Politzer, J. Mol. Model., 2012, 18, 541-548.

66. J. E. Del Bene, I. Alkorta and J. Elguero, J. Phys. Chem. A, 2013, 117, 11592-11604.

67. A. Bauzá and A. Frontera, Chem. Phys. Lett., 2015, 633, 282-286.

68. S. Roy, A. Bauza, A. Frontera, R. Banik, A. Purkayastha, M. G. B. Drew, B. M. Reddy, B. Sridhar, S. K. Das and S. Das, CrystEngComm, 2015, 17, 3912-3916.

69. C. Trujillo, G. Sanchez-Sanz, I. Alkorta and J. Elguero, New J. Chem., 2015, 39, 6791-6802.

70. T. Lang, X. Li, L. Meng, S. Zheng and Y. Zeng, Struct. Chem., 2015, 26, 213-221.

71. A. Bauza, T. J. Mooibroek and A. Frontera, Chem. Commun., 2015, 51, 1491-1493.

72. M. Solimannejad, N. Nassirinia and S. Amani, Struct. Chem., 2013, 24, 651-659.

73. G. Sánchez-Sanz, C. Trujillo, M. Solimannejad, I. Alkorta and J. Elguero, Phys. Chem. Chem. Phys., 2013, 15, 14310-14318.

74. A. Bauzá, R. Ramis and A. Frontera, J. Phys. Chem. A, 2014, 118, 2827-2834.

75. M. Solimannejad, V. Ramezani, C. Trujillo, I. Alkorta, G. Sánchez-Sanz and J. Elguero, J. Phys. Chem. A, 2012, 116, 5199-5206.

76. A. Bauza and A. Frontera, Phys. Chem. Chem. Phys., 2015, 17, 24748-24753.

77. I. Alkorta, J. Elguero and J. E. Del Bene, Chem. Phys. Lett., 2015, 641, 84-89. 
78. K. Haupa, A. Bil and Z. Mielke, J. Phys. Chem. A, 2015, 119, 10724-10734.

79. D. M. Bittner, D. P. Zaleski, S. L. Stephens, N. R. Walker and A. C. Legon, ChemPhysChem., 2015, 16, 2630-2634.

80. Q. Li, H. Zhuo, X. Yang, J. Cheng, W. Li and R. E. Loffredo, ChemPhysChem., 2014, 15, 500-506.

81. M. J. Frisch, G. W. Trucks, H. B. Schlegel, G. E. Scuseria, M. A. Robb, J. R. Cheeseman, G. Scalmani, V. Barone, B. Mennucci, G. A. Petersson, H. Nakatsuji, M. Caricato, X. Li, H. P. Hratchian, A. F. Izmaylov, J. Bloino, G. Zheng, J. L. Sonnenberg, M. Hada, M. Ehara, K. Toyota, R. Fukuda, J. Hasegawa, M. Ishida, T. Nakajima, Y. Honda, O. Kitao, H. Nakai, T. Vreven, J. Montgomery, J. A., J. E. Peralta, F. Ogliaro, M. Bearpark, J. J. Heyd, E. Brothers, K. N. Kudin, V. N. Staroverov, R. Kobayashi, J. Normand, K. Raghavachari, A. Rendell, J. C. Burant, S. S. Iyengar, J. Tomasi, M. Cossi, N. Rega, J. M. Millam, M. Klene, J. E. Knox, J. B. Cross, V. Bakken, C. Adamo, J. Jaramillo, R. Gomperts, R. E. Stratmann, O. Yazyev, A. J. Austin, R. Cammi, C. Pomelli, J. W. Ochterski, R. L. Martin, K. Morokuma, V. G. Zakrzewski, G. A. Voth, P. Salvador, J. J. Dannenberg, S. Dapprich, A. D. Daniels, O. Farkas, J. B. Foresman, J. V. Ortiz, J. Cioslowski and D. J. Fox, Wallingford, CT, Revision B.01 edn., 2009.

82. T. Helgaker, W. Klopper, H. Koch and J. Noga, J. Chem. Phys., 1997, 106, 9639-9646.

83. B. K. Mishra, S. Karthikeyan and V. Ramanathan, J. Chem. Theory Comput., 2012, 8, 1935-1942.

84. S. F. Boys and F. Bernardi, Mol. Phys., 1970, 19, 553-566.

85. A. E. Reed, F. Weinhold, L. A. Curtiss and D. J. Pochatko, J. Chem. Phys., 1986, 84, 5687-5705.

86. A. E. Reed, L. A. Curtiss and F. Weinhold, Chem. Rev., 1988, 88, 899-926.

87. E. D. Glendening, C. R. Landis and F. Weinhold, J. Comput. Chem., 2013, 34, 1429-1437.

88. $\quad$ R. F. W. Bader, Atoms in Molecules, A Quantum Theory, Clarendon Press, Oxford, 1990.

89. R. F. W. Bader, M. T. Carroll, J. R. Cheeseman and C. Chang, J. Am. Chem. Soc., 1987, 109, 79687979.

90. T. A. Keith, TK Gristmill Software, Overland Park KS2013.

91. K. Szalewicz and B. Jeziorski, in Molecular Interactions. From Van der Waals to Strongly Bound Complexes, ed. S. Scheiner, Wiley, New York1997, pp. 3-43.

92. R. Moszynski, P. E. S. Wormer, B. Jeziorski and A. van der Avoird, J. Chem. Phys., 1995, 103, 8058-8074.

93. H.-J. Werner, P. J. Knowles, F. R. Manby, M. Schütz, P. Celani, G. Knizia, T. Korona, R. Lindh, A. Mitrushenkov, G. Rauhut, T. B. Adler, R. D. Amos, A. Bernhardsson, A. Berning, D. L. Cooper, M. J. O. Deegan, A. J. Dobbyn, F. Eckert, E. Goll, C. Hampel, A. Hesselmann, G. Hetzer, T. Hrenar, G. Jansen, C. Köppl, Y. Liu, A. W. Lloyd, R. A. Mata, A. J. May, S. J. McNicholas, W. Meyer, M. E. Mura, A. Nicklaß, P. Palmieri, K. Pflüger, R. Pitzer, M. Reiher, T. Shiozaki, H. Stoll, A. J. Stone, R. Tarroni, T. Thorsteinsson, M. Wang and A. Wolf, Version 2006 edn., 2010.

94. J. P. Perdew, K. Burke and M. Ernzerhof, Phys. Rev. Lett., 1996, 77, 3865-3868.

95. L. M. Azofra and S. Scheiner, Phys. Chem. Chem. Phys., 2014, 16, 5142-5149.

96. L. M. Azofra and S. Scheiner, J. Chem. Phys., 2014, 140, 034302.

97. F. A. Bulat, A. Toro-Labbé, T. Brinck, J. S. Murray and P. Politzer, J. Mol. Model., 2010, 16, 16791691.

98. J. Poater, M. Solà and F. M. Bickelhaupt, Chem. Eur. J., 2006, 12, 2902-2905. 
Table 1. Energetic and geometric aspects of $\pi$-hole complexes XCN $\cdot \mathrm{NH}_{3}$

\begin{tabular}{|l|c|c|c|c|}
\hline $\mathrm{X}$ & $\begin{array}{c}\mathrm{E}_{\text {int }} \\
\mathrm{kcal} / \mathrm{mol}\end{array}$ & $\begin{array}{c}\mathrm{R}(\mathrm{C} \cdot \mathrm{N}) \\
\AA\end{array}$ & $\begin{array}{c}\Delta \mathrm{r}(\mathrm{C} \equiv \mathrm{N}) \\
\AA\end{array}$ & $\begin{array}{c}\theta(\mathrm{N} \cdot \mathrm{CN}) \\
\mathrm{degs}\end{array}$ \\
\hline $\mathrm{F}$ & 3.14 & 2.867 & 0.0002 & 96.0 \\
\hline $\mathrm{Cl}$ & 2.53 & 3.046 & 0.0000 & 87.5 \\
\hline $\mathrm{Br}$ & 2.43 & 3.072 & 0.0002 & 87.0 \\
\hline $\mathrm{I}$ & 2.44 & 3.104 & 0.0016 & 86.0 \\
\hline
\end{tabular}

Table 2. Energetic and geometric aspects of $\sigma$-hole complexes $\mathrm{NCX} \cdot \mathrm{NH}_{3}$

\begin{tabular}{|l|l|l|l|}
\hline $\mathrm{X}$ & $\begin{array}{l}\text { Eint } \\
\mathrm{kcal} / \mathrm{mol}\end{array}$ & $\begin{array}{l}\mathrm{R}(\mathrm{X} \cdot \mathrm{N}) \\
\AA\end{array}$ & $\begin{array}{l}\Delta \mathrm{r}(\mathrm{X}-\mathrm{C}) \\
\AA\end{array}$ \\
\hline $\mathrm{F}$ & 1.06 & 3.141 & -0.0025 \\
\hline $\mathrm{Cl}$ & 3.95 & 2.950 & 0.0051 \\
\hline $\mathrm{Br}$ & 5.62 & 2.880 & 0.0130 \\
\hline $\mathrm{I}$ & 8.24 & 2.852 & 0.0297 \\
\hline
\end{tabular}

Table 3. SAPT components $(\mathrm{kcal} / \mathrm{mol})$ of total interaction energy of $\pi$-hole complexes $\mathrm{XCN} \cdot \mathrm{NH}_{3}$

\begin{tabular}{|l|r|r|r|r|r|r|}
\hline $\mathrm{X}$ & \multicolumn{1}{|c|}{ ES } & \multicolumn{1}{c|}{ IND } & \multicolumn{1}{c|}{ DISP } & \multicolumn{1}{c|}{$\delta^{\mathrm{HF}}$} & \multicolumn{1}{c|}{ EX } & \multicolumn{1}{c|}{ TOTAL } \\
\hline $\mathrm{F}$ & -6.52 & -6.03 & -3.08 & -0.33 & 13.30 & -2.65 \\
\hline $\mathrm{Cl}$ & -4.26 & -3.63 & -2.77 & -0.22 & 8.85 & -2.03 \\
\hline $\mathrm{Br}$ & -4.06 & -4.04 & -2.81 & -0.23 & 9.19 & -1.95 \\
\hline $\mathrm{I}$ & -4.07 & -4.75 & -3.14 & 0.02 & 9.61 & -2.33 \\
\hline
\end{tabular}

Table 4. SAPT components $(\mathrm{kcal} / \mathrm{mol})$ of total interaction energy of $\sigma$-hole complexes $\mathrm{NCX} \cdot \mathrm{NH}_{3}$

\begin{tabular}{|l|r|r|r|r|r|r|}
\hline $\mathrm{X}$ & \multicolumn{1}{|c|}{ ES } & \multicolumn{1}{c|}{ IND } & \multicolumn{1}{c|}{ DISP } & \multicolumn{1}{c|}{$\delta^{\mathrm{HF}}$} & \multicolumn{1}{c|}{ EX } & \multicolumn{1}{c|}{ TOTAL } \\
\hline $\mathrm{F}$ & -1.66 & -1.35 & -0.81 & -0.09 & 2.99 & -0.92 \\
\hline $\mathrm{Cl}$ & -7.58 & -10.14 & -2.84 & -0.82 & 18.13 & -3.25 \\
\hline $\mathrm{Br}$ & -12.09 & -26.34 & -4.02 & -1.36 & 38.93 & -4.88 \\
\hline $\mathrm{I}$ & -19.18 & -53.72 & -5.45 & 8.41 & 57.24 & -12.71 \\
\hline
\end{tabular}


Table 5. Interaction Energies ( $\mathrm{kcal} / \mathrm{mol})$ of $\pi$-hole complexes $\mathrm{XCN} \cdot \mathrm{NH}_{3}$ calculated at various levels.

\begin{tabular}{|c|c|c|c|c|c|c|}
\hline & \multicolumn{3}{|c|}{ MP2/aug-cc-pV(X)Z } & & & \\
\hline $\mathrm{X}$ & $\mathrm{D}$ & $\mathrm{T}$ & Q & $\begin{array}{l}\text { CCSD(T)/ } \\
\text { aug-cc-pVDZ }\end{array}$ & MP2/CBS & CCSD(T)/CBS \\
\hline $\mathrm{F}$ & 3.14 & 3.56 & 3.78 & 2.92 & 3.94 & 3.72 \\
\hline $\mathrm{Cl}$ & 2.53 & 2.93 & 3.00 & 2.28 & 3.05 & 2.80 \\
\hline $\mathrm{Br}$ & 2.43 & 2.87 & 2.99 & 2.18 & 3.08 & 2.83 \\
\hline I & 2.44 & 2.88 & 3.05 & 2.19 & 3.17 & 2.92 \\
\hline
\end{tabular}

Table 6. Interaction Energies ( $\mathrm{kcal} / \mathrm{mol})$ of $\sigma$-hole complexes $\mathrm{NCX} \cdot \mathrm{NH}_{3}$ calculated at various levels

\begin{tabular}{|c|c|c|c|c|c|c|}
\hline & \multicolumn{3}{|c|}{ MP2/aug-cc-pV(X)Z } & & & \\
\hline $\mathrm{X}$ & $\mathrm{D}$ & $\mathrm{T}$ & $\mathrm{Q}$ & $\begin{array}{l}\text { CCSD(T)/ } \\
\text { aug-cc-pVDZ }\end{array}$ & $\mathrm{MP} 2 / \mathrm{CBS}$ & $\mathrm{CCSD}(\mathrm{T}) / \mathrm{CBS}$ \\
\hline $\mathrm{F}$ & 1.06 & 1.14 & 1.22 & 1.06 & 1.28 & 1.28 \\
\hline $\mathrm{Cl}$ & 3.95 & 4.28 & 4.52 & 3.79 & 4.70 & 4.54 \\
\hline $\mathrm{Br}$ & 5.62 & 6.01 & 6.23 & 5.31 & 6.39 & 6.08 \\
\hline I & 8.24 & 8.65 & 9.17 & 7.67 & 9.55 & 8.98 \\
\hline
\end{tabular}

Table 7. Interaction energies $(\mathrm{kcal} / \mathrm{mol})$ of five heterotrimer geometries of $\mathrm{XCN}\left(\mathrm{NH}_{3}\right)_{2}$

\begin{tabular}{|l|r|r|r|r|r|}
\hline & \multicolumn{1}{|c|}{$\mathrm{T}^{\mathrm{a}}$} & \multicolumn{1}{c|}{$\mathrm{T}^{\mathrm{a}}$} & \multicolumn{1}{c|}{$\mathrm{T} 3$} & $\mathrm{~T} 4$ & $\mathrm{~T} 5$ \\
\hline $\mathrm{F}$ & - & $5.66(6.28)$ & 6.26 & 8.58 & 5.00 \\
\hline $\mathrm{Cl}$ & $6.12(6.48)$ & $4.88(5.06)$ & 5.28 & 7.48 & 4.33 \\
\hline $\mathrm{Br}$ & $7.71(8.05)$ & $4.71(4.86)$ & 5.11 & 7.26 & 4.23 \\
\hline $\mathrm{I}$ & $10.38(10.68)$ & $4.72(4.88)$ & 5.05 & 7.21 & - \\
\hline
\end{tabular}

${ }^{\mathrm{a}}$ value in parentheses equals sum of dimer interactions

Table 8. Three-body term $\Delta^{3} \mathrm{E}(\mathrm{kcal} / \mathrm{mol})$ of heterotrimers of $\mathrm{XCN}\left(\mathrm{NH}_{3}\right)_{2}$

\begin{tabular}{|l|l|l|l|l|l|}
\hline & $\mathrm{T} 1$ & $\mathrm{~T} 2$ & $\mathrm{~T} 3$ & $\mathrm{~T} 4$ & $\mathrm{~T} 5$ \\
\hline $\mathrm{F}$ & - & 0.08 & -0.19 & -1.10 & -0.34 \\
\hline $\mathrm{Cl}$ & -0.08 & 0.01 & -0.04 & -0.86 & -0.21 \\
\hline $\mathrm{Br}$ & -0.09 & 0.02 & -0.03 & -0.85 & -0.19 \\
\hline $\mathrm{I}$ & -0.10 & 0.03 & -0.01 & -0.88 & - \\
\hline
\end{tabular}



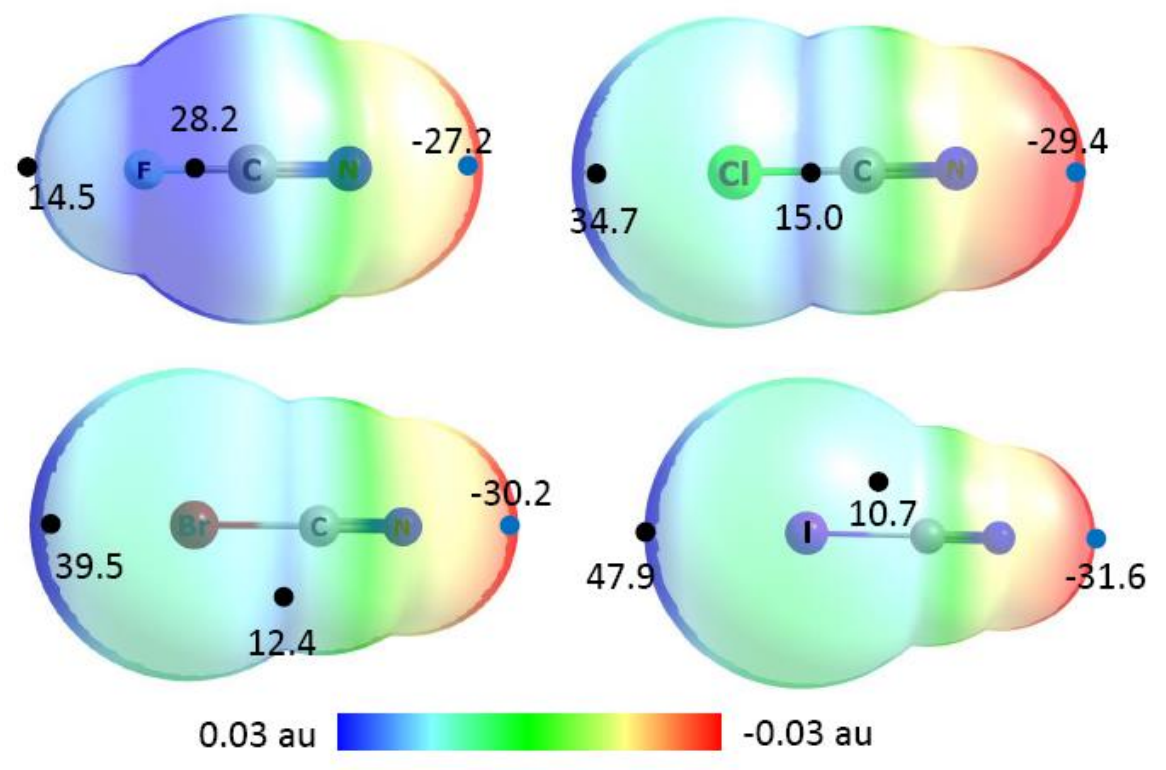

Fig 1. Molecular electrostatic potentials (MEPs) of XCN molecules. Black and blue dots respectively indicate positions of maxima and minima on the 0.001 au isodensity surface, with values displayed in $\mathrm{kcal} / \mathrm{mol}$.
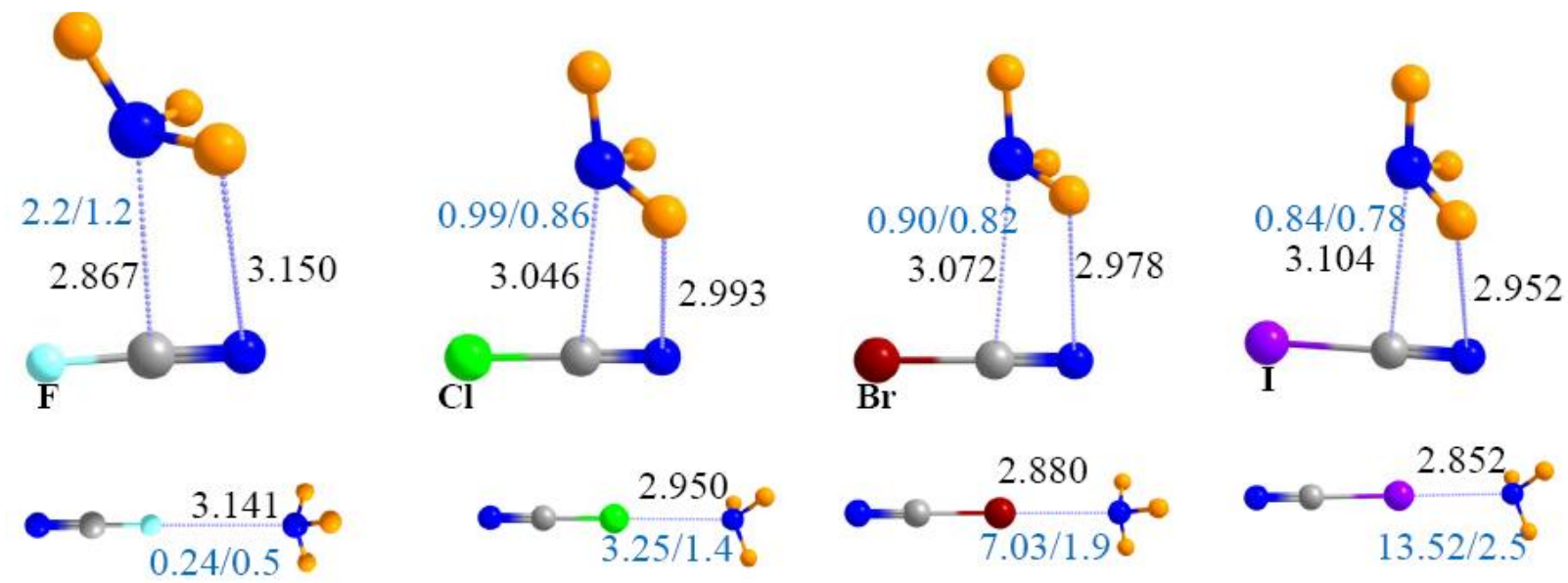

Fig 2. Optimized geometries of $\pi$-hole (top) and $\sigma$-hole (bottom) dimers of $\mathrm{NH}_{3}$ with $\mathrm{XCN}$. Distances are in $\AA$. Blue numbers refer to $\mathrm{NBO}$ values of $\mathrm{E}(2)$, in $\mathrm{kcal} / \mathrm{mol}$, for transfer from $\mathrm{N}$ lone pair to $\pi^{*}(\mathrm{CN})$ (top) and $\sigma^{*}(\mathrm{XC})$ (bottom). Number to right of slash indicates electron density $\left(10^{-2} \mathrm{au}\right)$ at AIM bond critical point. 

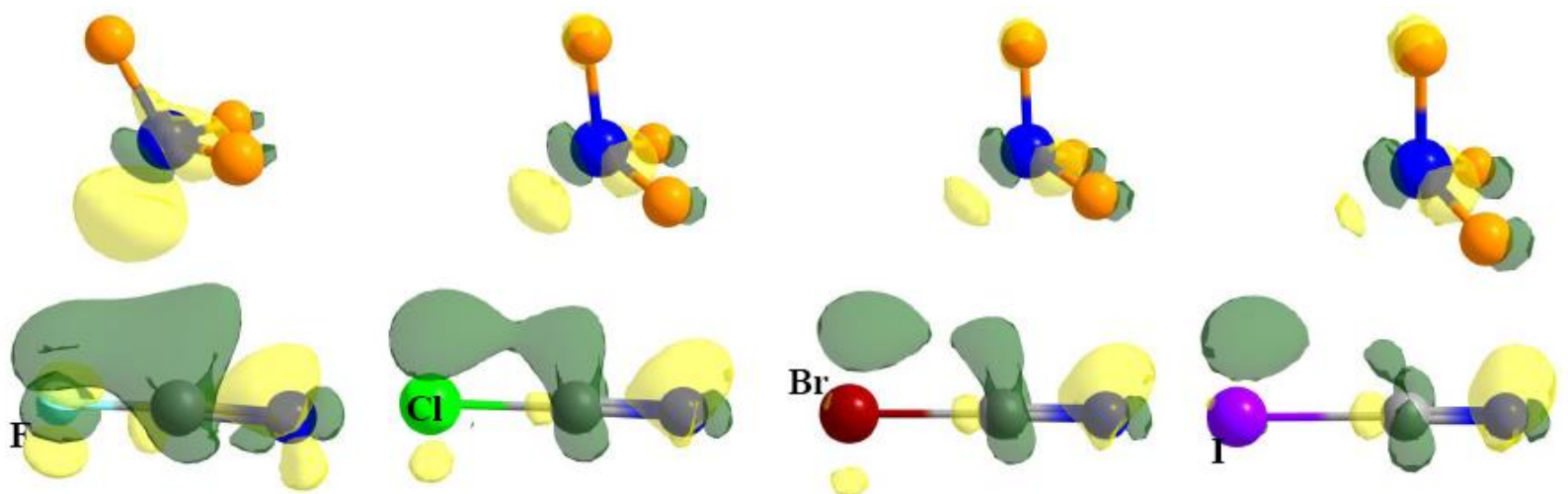

Fig 3. Electron density shifts that arise from formation of $\pi$-hole complexes. Yellow and green regions respectively correspond to gain and loss of electron density, on the \pm 0.0005 au contour. 

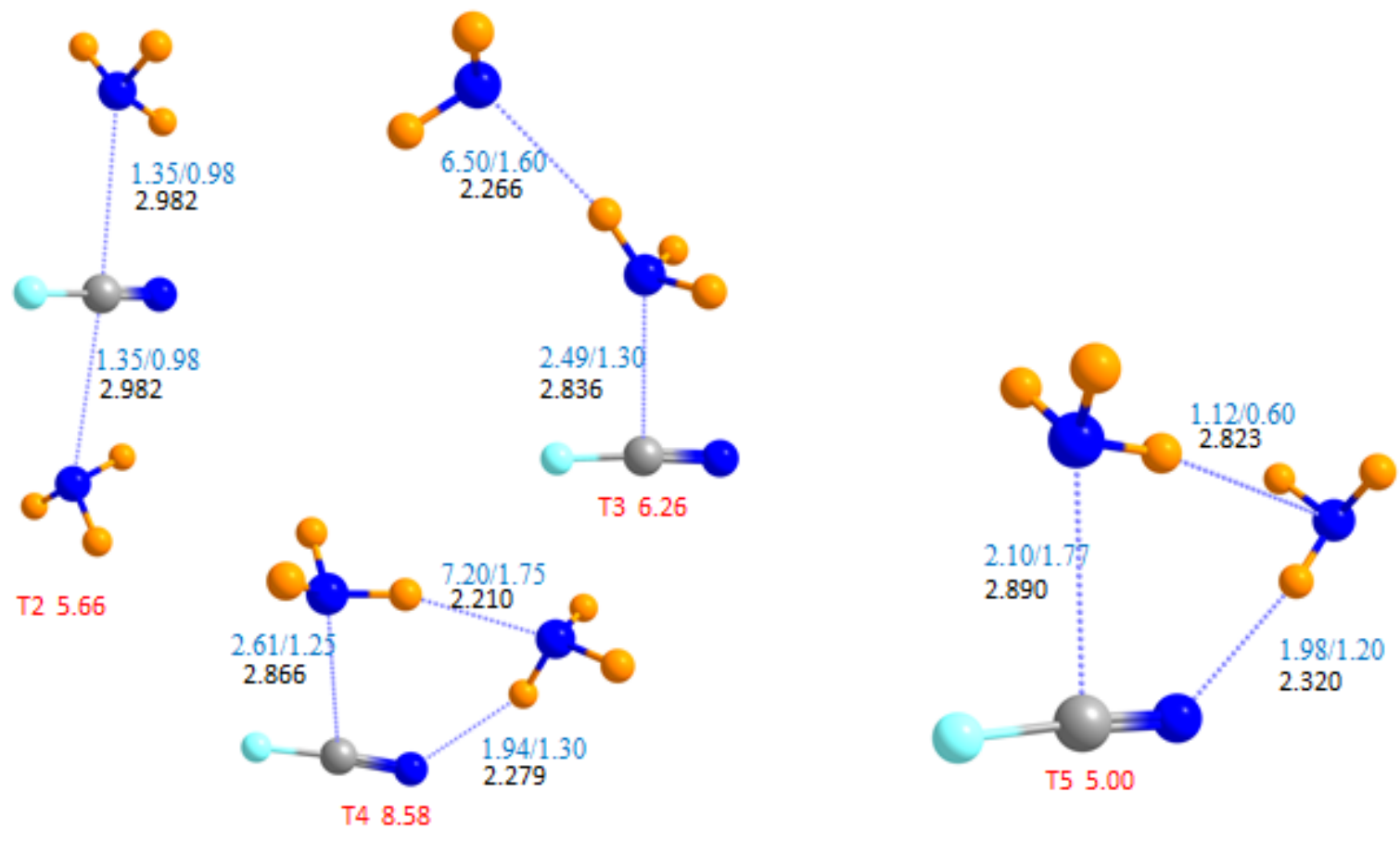

Fig 4. Optimized geometries of 2:1 heterotrimers of $\mathrm{NH}_{3}$ with $\mathrm{FCN}$. Red number indicates total interaction energy in $\mathrm{kcal} / \mathrm{mol}$. Distances are in $\AA$ in black. Blue numbers refer to NBO values of $\mathrm{E}(2)$, in $\mathrm{kcal} / \mathrm{mol}$, for transfer from $\mathrm{N}$ lone pair to $\pi^{*}(\mathrm{CN})$ or $\sigma^{*}(\mathrm{XC})$. Number to right of slash indicates electron density $\left(10^{-2} \mathrm{au}\right)$ at AIM bond critical point. 

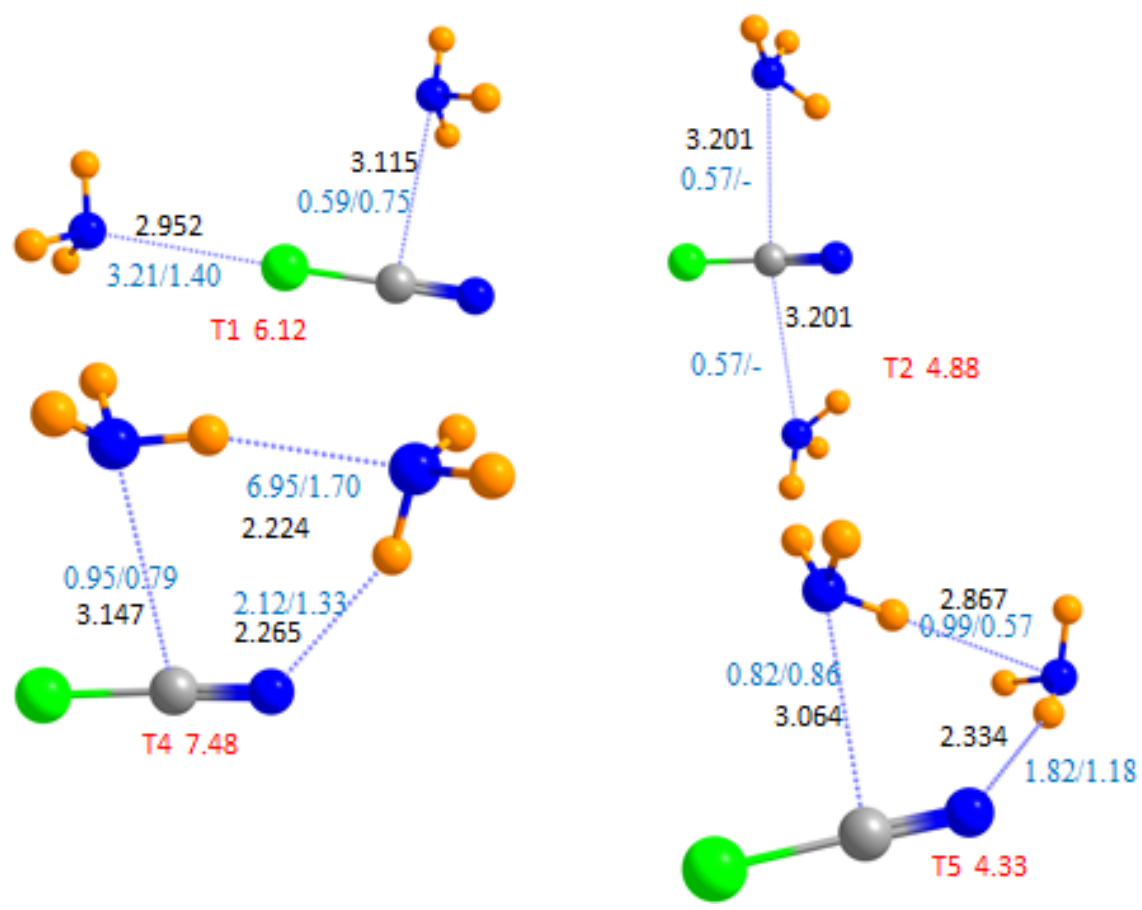

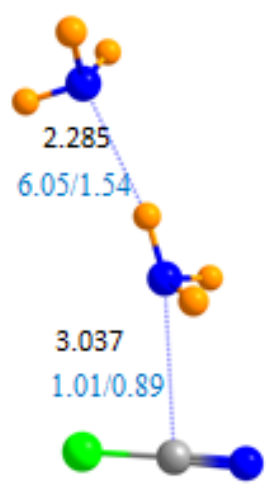

T3 5.28

Fig 5. Optimized geometries of 2:1 heterotrimers of $\mathrm{NH}_{3}$ with $\mathrm{ClCN}$. Red number indicates total interaction energy in $\mathrm{kcal} / \mathrm{mol}$. Distances are in $\AA$ in black. Blue numbers refer to NBO values of $\mathrm{E}(2)$, in $\mathrm{kcal} / \mathrm{mol}$, for transfer from $\mathrm{N}$ lone pair to $\pi^{*}(\mathrm{CN})$ or $\sigma^{*}(\mathrm{XC})$. Number to right of slash indicates electron density $\left(10^{-2} \mathrm{au}\right)$ at AIM bond critical point. 

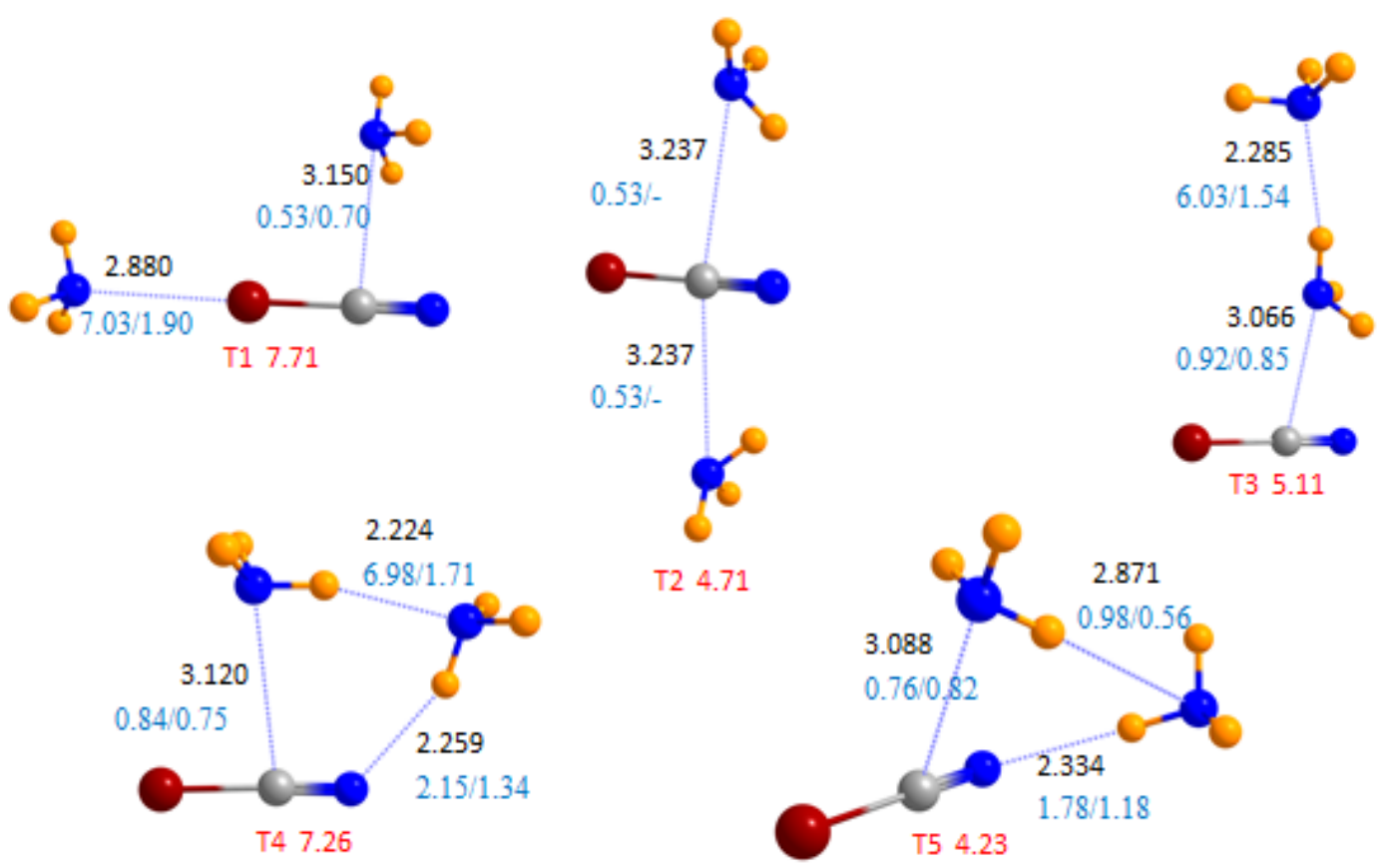

Fig 6. Optimized geometries of 2:1 heterotrimers of $\mathrm{NH}_{3}$ with $\mathrm{BrCN}$. Red number indicates total interaction energy in $\mathrm{kcal} / \mathrm{mol}$. Distances are in $\AA$ in black. Blue numbers refer to NBO values of $\mathrm{E}(2)$, in $\mathrm{kcal} / \mathrm{mol}$, for transfer from $\mathrm{N}$ lone pair to $\pi^{*}(\mathrm{CN})$ or $\sigma^{*}(\mathrm{XC})$. Number to right of slash indicates electron density $\left(10^{-2} \mathrm{au}\right)$ at AIM bond critical point. 


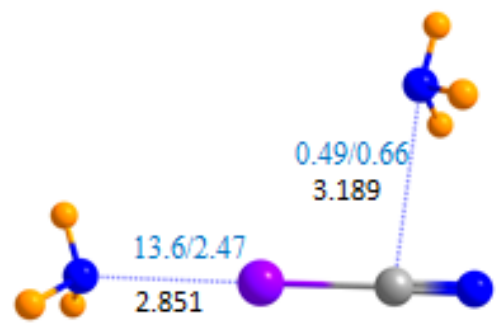

T1 10.38

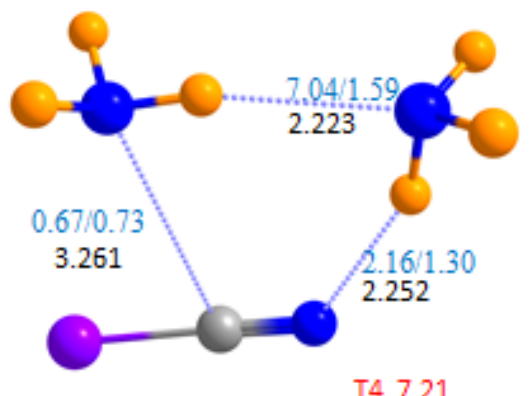

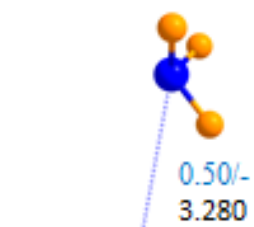

3.280
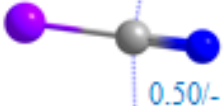

3.280

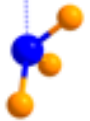

T2 4.72

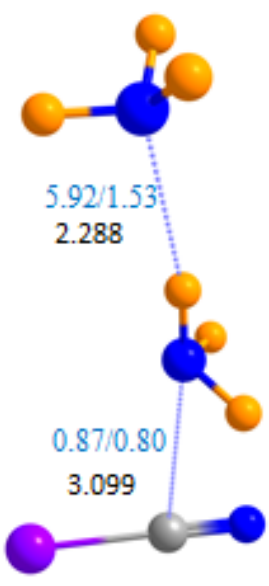

T3 5.05

Fig 7. Optimized geometries of 2:1 heterotrimers of $\mathrm{NH}_{3}$ with $\mathrm{ICN}$. Red number indicates total interaction energy in $\mathrm{kcal} / \mathrm{mol}$. Distances are in $\AA$ in black. Blue numbers refer to NBO values of $\mathrm{E}(2)$, in $\mathrm{kcal} / \mathrm{mol}$, for transfer from $\mathrm{N}$ lone pair to $\pi^{*}(\mathrm{CN})$ or $\sigma^{*}(\mathrm{XC})$. Number to right of slash indicates electron density $\left(10^{-2} \mathrm{au}\right)$ at AIM bond critical point. 